\title{
Assessment of Fetal Gestational Age in Different Trimesters from Ultrasonographic Measurements of Biparietal Diameter in the Region of Udaipur
}

\author{
Hina Sharma', Dharamanjai Kumar Sharma ${ }^{2}$, lla Sharma ${ }^{3}$ \\ ${ }^{1}$ Assistant Professor, Geetanjali Medical College and Hospital, Udaipur, Postal address: 22, Hazareshwar Colony, Udaipur, ${ }^{2}$ Senior Professor, Department \\ of Surgery, Rabindra Nath Tagore Medical College, Udaipur, ${ }^{3}$ Final Year M.B.B.S. Student, Rabindra Nath Medical College, Udaipur.
}

\section{Abstract}

\begin{abstract}
Introduction: Precise estimation of gestational age is the key to proper antepartum care. Ultrasonographic estimation of fetal age using various fetal parameters is utilized for accurate estimation because estimation by last menstrual period is not reliable in all cases. Objectives: To assess gestational age with the help of ultrasonographic measurements of fetal biparietal diameter in the local population of the region of Udaipur district of Rajasthan and thereby evaluate significance of this fetal biometric parameter in the prediction of gestational age by ultrasound. Subjects and Methods: Data of Ultrasonographic measurements and patient history was taken from the past records. Statistical analysis: Mean, standard deviation, statistical significance and t test were calculated. Results: The ultrasonographic measurement of biparietal diameter is a reliable indicator of gestational age in second and third trimesters. Conclusion: The derived gestational age is comparable with that used by Hadlock et al.
\end{abstract}

Keywords: Gestational age, fetal parameters.

Corresponding Author: Dr. Dharamanjai Kumar Sharma, Senior Professor, Department of Surgery, Rabindra Nath Tagore Medical College, Udaipur.

Received: December 2019

Accepted: December 2019

\section{Introduction}

Gestational age (GA) refers to the length of pregnancy after the first day of the last menstrual period (LMP) and is usually expressed in weeks or days. The precise estimation of gestational age is the key for successful antepartum care and judicious explanation of antenatal tests and successful planning of appropriate intervention or treatment. Failure of accurate gestational age assessment can result in iatrogenic prematurity or postmaturity, both of which are associated with increased perinatal mortality and morbidity. ${ }^{[1]}$

Last menstrual period (LMP) cannot be used for all patients because $10-40 \%$ of all patients seen in the antenatal clinics have no knowledge of their LMPs.

Ultrasound gives a more objective evidence of gestational age. ${ }^{[2,3]}$ The most commonly used fetal biometric parameters are crown-rump length, fetal biparietal diameters (BPD), head circumference (HC), abdominal circumference (AC), and femur length (FL) to determine gestational age. ${ }^{[4]}$

Many existing references for biometric measurements have been reported by a number of investigators with results that show the uniqueness to their setting. ${ }^{[5-9]}$ The fetal biometric charts used in Udaipur are set from a different geographical setting, race and nutritional status. It is therefore important to conduct a study to investigate the reliability of the presently used references.
Therefore, this study was undertaken to assess the gestational age in the second and third trimesters with the help of sonographic measurements of biparietal diameter of fetus in the local population. The results of this study will help in creating a base line data on estimation of the gestational age in the region of Udaipur.

\section{Aims and Objectives}

Objectives of the study:

1. To assess gestational age in the second and third trimesters with the help of ultrasonographic measurements of fetal biometric parameter- biparietal diameter in the local population of the region of Udaipur district of Rajasthan.

2. To evaluate significance of this fetal biometric parameter in the prediction of gestational age by ultrasound.

\section{Subjects and Methods}

\section{Source of data:}

Subjects for the study were Pregnant women of Udaipur region registered for antenatal care (ANC) in Geetanjali Medical College and Rabindranath Tagore Medical College, Udaipur. Data was collected from the medical record department. 


\section{Methodology:}

The study design of the current study is of retrospective type.

\section{Sample Size Estimation}

All cases of second and third trimesters from 1st June 2012 to 18th December 2014, that fulfilled the inclusion criteria, were included in the study.

\section{Ethical Considerations}

Ethical clearance was obtained.

\section{Inclusion Criteria}

1. Only singleton pregnancies ( 12 weeks to 41 weeks) were included.

2. Expectant mothers with history of regular menstrual cycles and known last menstrual period.

\section{Exclusion Criteria}

1. Anomalous fetuses

2. Patients with unknown LMP

3. Multiple gestation

4. Known history of maternal disease- Hypertension, Diabetes Mellitus

Sample size -1212

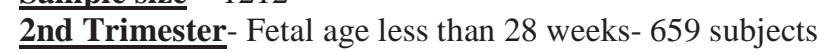
3rd Trimester- Fetal age more than 28 weeks- 553 subjects

Method of collecton of data: Past record of sonography reports of fetus of pregnant women were obtained from the radiology department and medical records department.

\section{Method of Assessment Done}

Difference in gestational age by clinical and USG (Ultrasonography) method, in the 2nd trimester and 3rd trimester, was calculated. Mean of parameters was calculated. Comparison of mean of parameters of present study with standard fetal growth charts in 2nd and 3rd trimesters was done.

Student's t test was used for finding statistical significance.

Parameters were assessed by calculating mean, regression coefficient and t test was applied for testing the level of significance. Statistical significance of the parameter (Biparietal diameter) in the prediction of gestational age by ultrasound was evaluated.

\section{Results}

Mean Biparietal Diameter was obtained for each gestational week determined by LMP. The range of measurements in each week and the standard error of mean and standard deviation were also seen. Mean biparietal diameter at term was found to be $88.4 \mathrm{~cm}$ with a standard deviation of $1 \mathrm{~cm}$ [Table 1].

Table 1: Mean biparietal diameter per gestational week (LMP); Standard Error of Mean and Standard Deviation

\begin{tabular}{|c|c|c|c|c|c|c|}
\hline \multirow{2}{*}{$\begin{array}{l}\text { GA by LMP } \\
\text { (weeks) }\end{array}$} & \multicolumn{6}{|c|}{ BPD (mm) } \\
\hline & Mean & Minimum & Maximum & Range & Standard Error of Mean & Standard Deviation \\
\hline $15.01-16.00$ & 34.0 & 27.8 & 39.3 & 11.5 & 1.4 & 3.6 \\
\hline $16.01-17.00$ & 35.3 & 26.4 & 49.4 & 23.0 & .7 & 4.4 \\
\hline $17.01-18.00$ & 39.0 & 25.9 & 70.3 & 44.4 & .7 & 5.5 \\
\hline $18.01-19.00$ & 42.3 & 31.5 & 49.1 & 17.6 & .4 & 3.4 \\
\hline $19.01-20.00$ & 45.0 & 40.1 & 52.6 & 12.5 & .4 & 3.0 \\
\hline $20.01-21.00$ & 48.4 & 39.2 & 58.5 & 19.3 & .5 & 3.8 \\
\hline $21.01-22.00$ & 50.8 & 39.4 & 58.8 & 19.4 & .4 & 3.5 \\
\hline $22.01-23.00$ & 52.5 & 34.4 & 63.2 & 28.8 & .6 & 4.7 \\
\hline $23.01-24.00$ & 57.1 & 48.4 & 73.2 & 24.8 & .6 & 3.7 \\
\hline $24.01-25.00$ & 60.1 & 51.6 & 72.1 & 20.5 & .7 & 4.2 \\
\hline $25.01-26.00$ & 62.8 & 49.6 & 73.0 & 23.4 & .7 & 4.9 \\
\hline $26.01-27.00$ & 65.4 & 30.2 & 72.7 & 42.5 & .7 & 5.8 \\
\hline $27.01-28.00$ & 68.4 & 54.3 & 77.8 & 23.5 & .5 & 4.3 \\
\hline $28.01-29.00$ & 72.6 & 58.0 & 81.3 & 23.3 & 1.5 & 6.2 \\
\hline $29.01-30.00$ & 72.6 & 61.3 & 79.4 & 18.1 & 1.4 & 4.7 \\
\hline $30.01-31.00$ & 77.3 & 71.0 & 82.1 & 11.1 & .9 & 3.3 \\
\hline $31.01-32.00$ & 80.9 & 71.2 & 92.7 & 21.5 & 1.1 & 4.7 \\
\hline $32.01-33.00$ & 80.0 & 63.5 & 89.9 & 26.4 & 1.0 & 5.4 \\
\hline $33.01-34.00$ & 82.1 & 71.5 & 90.9 & 19.4 & .6 & 3.7 \\
\hline $34.01-35.00$ & 84.8 & 75.3 & 93.2 & 17.9 & .6 & 4.1 \\
\hline $35.01-36.00$ & 85.8 & 74.9 & 92.8 & 17.9 & .4 & 3.6 \\
\hline $36.01-37.00$ & 87.4 & 62.2 & 95.8 & 33.6 & .5 & 4.5 \\
\hline $37.01-38.00$ & 88.3 & 76.0 & 97.1 & 21.1 & .4 & 3.8 \\
\hline $38.01-39.00$ & 89.2 & 74.5 & 96.8 & 22.3 & .4 & 3.9 \\
\hline $39.01-40.00$ & 88.8 & 73.9 & 97.1 & 23.2 & .8 & 4.9 \\
\hline $40.01-41.00$ & 90.2 & 84.6 & 97.2 & 12.6 & 1.0 & 3.6 \\
\hline $41.01-42.00$ & 88.4 & 87.3 & 89.1 & 1.8 & .6 & 1.0 \\
\hline$>42$ & 86.6 & 83.9 & 91.9 & 8.0 & 1.8 & 3.6 \\
\hline
\end{tabular}

Table 2: Mean gestational age (weeks) by USG per LMP gestational age (week)

\begin{tabular}{|l|l|l|l|l|l|l|}
\hline GA (weeks) by & USG GA & Minimum & Maximum & Range & Standard Error of Mean \\
\cline { 2 - 7 } LMP & Mean & 14.71 & 17.29 & 2.57 & .30 & Standard Deviation \\
\hline $15.01-16.00$ & 16.18 & 14.57 & 20.86 & 6.29 & .17 & .79 \\
\hline $16.01-17.00$ & 16.73 & 14.29 & 28.86 & 14.57 & .23 & 1.08 \\
\hline $17.01-18.00$ & 17.84 & 16.00 & 20.86 & 4.86 & .11 \\
\hline $18.01-19.00$ & 18.69 & 1.74 & .89 \\
\hline
\end{tabular}


Sharma et al; Assessment of fetal gestational age

\begin{tabular}{|l|l|l|l|l|l|l|}
\hline $19.01-20.00$ & 19.53 & 18.00 & 23.29 & 5.29 & .12 & .90 \\
\hline $20.01-21.00$ & 20.80 & 18.43 & 30.86 & 12.43 & .23 & 1.74 \\
\hline $21.01-22.00$ & 21.63 & 17.57 & 30.57 & 13.00 & .20 & 1.56 \\
\hline $22.01-23.00$ & 22.03 & 16.43 & 24.43 & 8.00 & .20 & 1.44 \\
\hline $23.01-24.00$ & 23.54 & 20.71 & 29.29 & 8.57 & .19 & 1.25 \\
\hline $24.01-25.00$ & 24.56 & 21.57 & 29.00 & 7.43 & .21 & 1.31 \\
\hline $25.01-26.00$ & 25.50 & 21.29 & 29.43 & 8.14 & .21 & 1.40 \\
\hline $26.01-27.00$ & 26.23 & 15.57 & 28.86 & 13.29 & .25 & 2.09 \\
\hline $27.01-28.00$ & 27.29 & 23.00 & 29.71 & 6.71 & .16 & 1.31 \\
\hline $28.01-29.00$ & 28.93 & 24.43 & 33.14 & 8.71 & .50 & 2.14 \\
\hline $29.01-30.00$ & 28.98 & 24.00 & 31.29 & 7.29 & .57 & .27 \\
\hline $30.01-31.00$ & 30.72 & 29.29 & 32.57 & 3.29 & .38 & 1.98 \\
\hline $31.01-32.00$ & 31.91 & 28.57 & 35.00 & 6.43 & .39 \\
\hline $32.01-33.00$ & 31.96 & 26.00 & 36.00 & 10.00 & .39 & 1.60 \\
\hline $33.01-34.00$ & 33.18 & 28.29 & 35.86 & 7.57 & .26 & 2.10 \\
\hline $34.01-35.00$ & 34.04 & 30.00 & 37.86 & 7.86 & .27 & .17 \\
\hline $35.01-36.00$ & 34.66 & 31.43 & 37.71 & 6.29 & .17 & 1.76 \\
\hline $36.01-37.00$ & 35.24 & 25.14 & 38.57 & 13.43 & .18 & 1.33 \\
\hline $37.01-38.00$ & 35.94 & 32.00 & 38.86 & 6.86 & .15 & 1.74 \\
\hline $38.01-39.00$ & 36.07 & 25.43 & 39.43 & 14.00 & .21 & 1.46 \\
\hline $39.01-40.00$ & 36.06 & 29.00 & 39.14 & 10.14 & .31 & 1.81 \\
\hline $40.01-41.00$ & 36.82 & 34.71 & 39.71 & 5.00 & .43 & 1.90 \\
\hline $41.01-42.00$ & 32.71 & 26.14 & 36.86 & 10.71 & 3.32 & \\
\hline$>42$ & 35.00 & 33.86 & 36.86 & 3.00 & .66 & \\
\hline
\end{tabular}

Table 3: Mean gestational age determined from measurements of biparietal diameter

\begin{tabular}{|c|c|c|c|}
\hline BPD (mm) & GA (BPD) Mean & BPD (mm) & GA (BPD) Mean \\
\hline 26 & 14.57 & 63 & 25.34 \\
\hline 27 & 14.62 & 64 & 25.70 \\
\hline 28 & 15.00 & 65 & 26.12 \\
\hline 29 & 15.14 & 66 & 26.46 \\
\hline 30 & 15.43 & 67 & 26.85 \\
\hline 31 & 15.64 & 68 & 27.23 \\
\hline 32 & 15.79 & 69 & 27.63 \\
\hline 33 & 16.16 & 70 & 27.98 \\
\hline 34 & 16.39 & 71 & 28.33 \\
\hline 35 & 16.65 & 72 & 28.73 \\
\hline 36 & 16.97 & 73 & 29.12 \\
\hline 37 & 17.18 & 74 & 29.55 \\
\hline 38 & 17.48 & 75 & 29.96 \\
\hline 39 & 17.72 & 76 & 30.34 \\
\hline 40 & 18.03 & 77 & 30.73 \\
\hline 41 & 18.27 & 78 & 31.12 \\
\hline 42 & 18.58 & 79 & 31.43 \\
\hline 43 & 18.88 & 80 & 32.31 \\
\hline 44 & 19.16 & 81 & 32.36 \\
\hline 45 & 19.44 & 82 & 32.67 \\
\hline 46 & 19.79 & 83 & 33.16 \\
\hline 47 & 20.08 & 84 & 33.70 \\
\hline 48 & 20.41 & 85 & 34.08 \\
\hline 49 & 20.71 & 86 & 34.48 \\
\hline 50 & 21.01 & 87 & 34.93 \\
\hline 51 & 21.28 & 88 & 35.34 \\
\hline 52 & 21.54 & 89 & 35.82 \\
\hline 53 & 21.95 & 90 & 36.19 \\
\hline 54 & 22.24 & 91 & 36.69 \\
\hline 55 & 22.61 & 92 & 37.10 \\
\hline 56 & 22.99 & 93 & 37.47 \\
\hline 57 & 23.25 & 94 & 38.04 \\
\hline 58 & 23.65 & 95 & 38.52 \\
\hline 59 & 24.03 & 96 & 39.00 \\
\hline 60 & 24.34 & 97 & 39.57 \\
\hline 61 & 24.64 & 98 & 39.71 \\
\hline 62 & 25.02 & & \\
\hline
\end{tabular}

Mean Gestational age (weeks) by USG was obtained for each gestational week determined by LMP. The range of measurements in each week and the standard error of mean and standard deviation were also seen [Table 2].
Mean Gestational Age was determined from measurements of Biparietal Diameter [Table 3].

Gestational age (week) curve was obtained by biparietal diameter measurements [Figure 1]. 


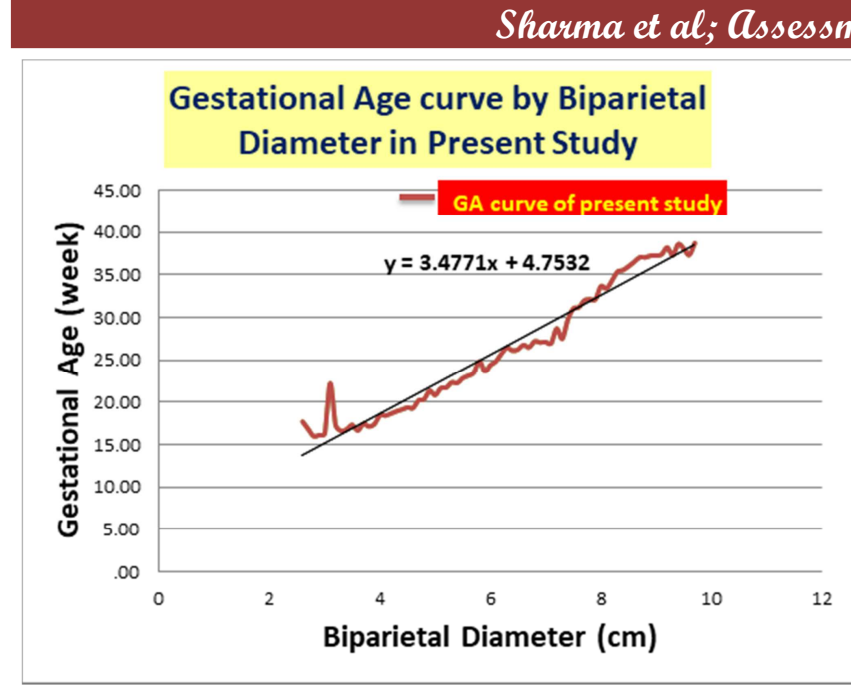

Figure 1: Gestational age (week) curve obtained by biparietal diameter measurements

The regression equation for determination of gestational age from biparietal diameter is

$\mathrm{y}=3.477 \mathrm{x}+4.753$

$\mathrm{y}=$ Gestational Age (weeks)

$\mathrm{x}=$ Biparietal diameter $(\mathrm{cm})$

Correlation between gestational age by LMP method and biparietal diameter was calculated.

Correlation coefficient $r=0.98$

Degrees of freedom $\mathrm{df}=70$

The closer a correlation value is to +1 the stronger the positive correlation. The closer a value is to -1 , the stronger the negative correlation.

Gestational age determined by sonography and LMP methods were compared [Figure 2].

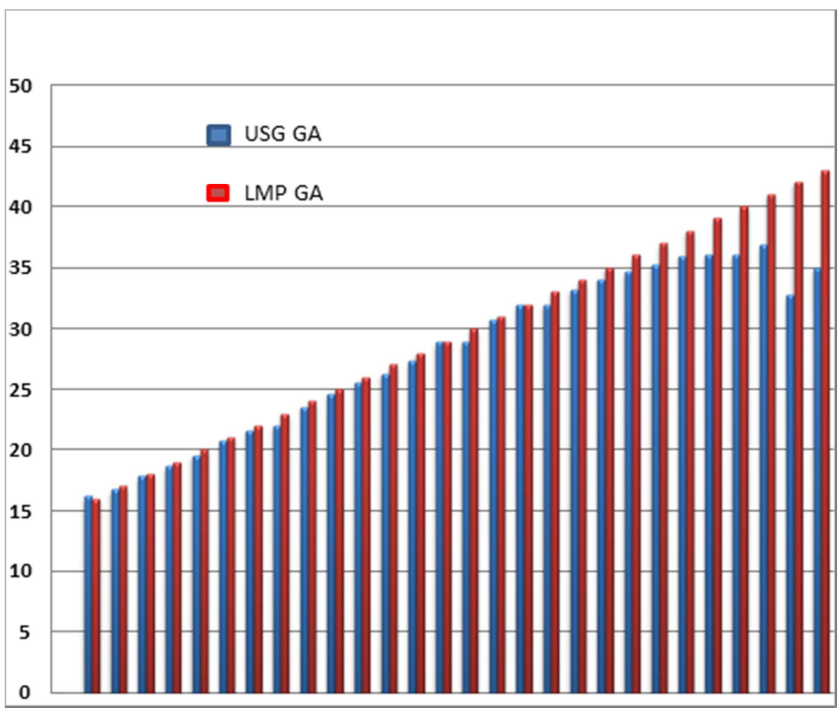

Figure 2: Comparison of gestational age determined by sonography and LMP methods

This concludes that the difference in gestational age determined by fetal parameter and LMP method is not significant.

Statistical significance was calculated [Table 4].
Table 4: Statistical significance determination of fetal age by fetal biometric parameter

Statistical significance

\begin{tabular}{|l|l|l|}
\hline & BPD & USG (All Parameters) \\
\hline $2^{\text {nd }}$ Trimester & 0.33 & 0.39 \\
\hline $3^{\text {rd }}$ Trimester & 0.43 & 0.03 \\
\hline
\end{tabular}

Student's t test was applied for fetal parameter for second and third trimesters. However, the gestational age determined by BPD was not significantly different from menstrual age $(\mathrm{P}>0.05)$.

\section{Discussion}

In the present study average full term baby's biparietal diameter was found to be 88.4 with a standard deviation of 1 $\mathrm{cm}$ [Table 3] as compared to $95-100 \mathrm{~cm}$ shown in text. ${ }^{[10]}$

In the present study mean gestational age by USG at term (42 weeks by LMP) was found to be 32.7 weeks with a standard deviation of 5.8 weeks. Mean gestational age by USG at 28 weeks (LMP) was 27.29 weeks with a standard deviation of just 1.31 weeks. It shows that gestational age obtained in the second trimester was more accurate compared to that obtained in the third trimester.

Present study shows that gestational age obtained by USG measurements in the second trimester was more accurate compared to that obtained in the third trimester.

A study on population of Africa also showed no significant ethnic differences between mothers in fetal biometry at second trimester. They support the recommendation that ultrasound in practical health care can be used to assess gestational age in various populations with little risk of error due to ethnic variation. ${ }^{[11]}$ These results are similar to the results of the present study.

A study of fetal biometry at 14-40 weeks' gestation by Snijders showed that despite methodological differences between the various studies, the mean, 5th and 95th centiles were essentially the same, ${ }^{[12]}$ conforming to our study.

Another previous study of fetal ultrasound biometry on Puerto Recan population, by Alberto de la Vega showed similar fetal growth patterns as those reported from mixed U.S. populations, ${ }^{[13]}$ thus validating the present study.

Thereby we see that previous studies validate the findings of the present study. However some studies by previous workers have shown contrasting results. A study by Sumit Babuta on a population of Jaipur, Rajasthan saw that sonography at 18 weeks underestimated gestational age compared with the LMP date by a median of -1.4 days. Fetal $\mathrm{AC}$ and BPD were markedly smaller than the Western references at 18 weeks. In late pregnancy (26 weeks and 36 weeks), all measurements were smaller than the European references. The deficit was greatest for AC and BPD. ${ }^{[14]}$ Conclusion of this study was that variation in predicted gestational age by ultrasonography is attributed to the anthropometric difference between the two populations due to racial, genetic, nutritional, and socioeconomic factors[14]. This is contrary to our study.

Another study by Kinare on Indian rural population shows contradictory results. His study also shows that the growth of rural Indian fetuses differs from the Western sonographic references that are generally used in clinical practice in 


\section{Shauma et al; Assessment of fetal gestatianal age}

India. ${ }^{[15]}$ In our study the data consists of a mixed rural and urban population, yet our sonographic references are not significantly different from the Western ones.

Gestational age curve derived from the measurements of Biparietal Diameter by Hadlock et al was compared with our study. [Figure 3] shows the comparison between the two curves. It revealed no significant difference between the two curves. ( $\mathrm{P}$ value 0.33 for 2 nd trimester and 0.43 for $3 \mathrm{rd}$ trimester).

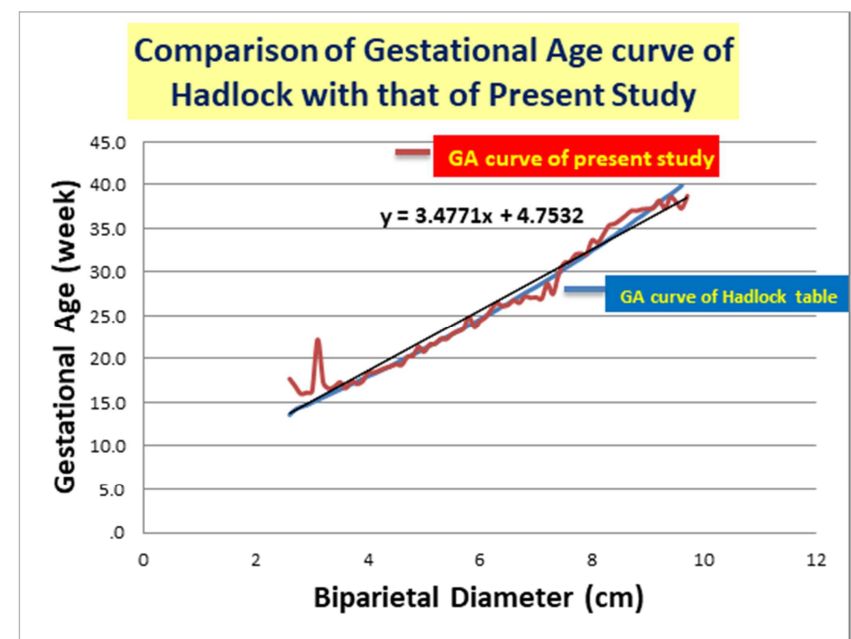

Figure 3: Comparison of gestational age curve derived from BPD measurements of present study with that of Hadlock et al.

The regression equation for calculation of Gestational Age in weeks from Biparietal Diameter in the present study is: $y=3.477 x+4.753$ where ' $x$ ' is the Biparietal Diameter and ' $y$ ' is Gestational Age.

This study showed that ultrasonographic measurement of biparietal diameter is a reliable indicator of gestational age in second and third trimesters.

Therefore, although we do not have fetal biometric measurement charts for the population of Udaipur, Rajasthan, the measurements adopted from Hadlock et al tables correlates very well with gestation age derived from last normal menstrual period of our pregnant mothers.

The derived gestational age is comparable with that of Hadlock et al.

Thus our results support the use of conventional fetal sonographic biometric standards derived from foreign population for the population of Udaipur.

However, this study provides base line data for indigenous population and the nomograms can be gainfully employed for further studies.

\section{Strengths of the Present Study}

- The data collected is from two medical colleges in Udaipur that cater to the general population of Udaipur region.

- All cases that met our selection criteria were taken thus removing selection bias.

- Detailed comparison with various previous studies was done.

- Regression tables for the local population of Udaipur region for determining gestational age by ultrasonography by fetal biometric parameter - Biparietal diameter have been presented.

- Data of the present study can be used for further studies and research.

\section{Limitations of the Present Study}

- Same pregnant woman could not be followed up for progress of pregnancy and any variation thereof.

- Date of actual delivery of the women could not be traced as the data was collected from the medical records department. Thus it could not be compared by EDD.

- Nutritional and economic status of mother could not be assessed.

- New born parameters could not be measured after the birth of the baby.

- Sex of the fetus was not determined/ mentioned in records due to prohibition of determination of gender. As such differences, if any, among the parameters of male and female fetuses could not be determined.

\section{Recommendations}

Tertiary care centres should keep a record of the maternal details along with socioeconomic status and serial investigations throughout pregnancy in one place. Postdelivery details should also be recorded in the same place. This will be beneficial for further research, thus ultimately benefiting maternal and child health.

\section{Conclusion}

Thus it can be concluded that although the present study has derived a regression table for the local population of Udaipur region, yet the conventional fetal sonographic biometric standards derived from foreign population can be used for Udaipur region to determine age of the fetus by ultrasonographic measurement of BPD.

\section{References}

1. Konje JC, Abrams KR, Bell SC, Taylor DJ. Determination of gestational age after the 24th week of gestation from fetal kidney length measurements. Ultrasound Obstet Gynecol. 2002 Jun; 19(6): p. $592-597$.

2. Fernandes J. Estimation of gestational age in third trimester using mean fetal renal length. ( Carlo Otto, Lawrence D Platt. Obstetrics and Gynaecology Clinics of North America. December 1991;18 (4):907). Dissertation reference. 2011.

3. Deter RL, Harrist RB, Hadlock FP, Poindexter AN. Longitudinal studies of fetal growth with use of dynamic image ultrasonography. Am. J. Obstet. Gynecol. 1982;(143).

4. Sabbagha RE, Hugley M. Standardization of sonar cephalometry and gestational age. Obstet. Gynecol. 1978;(52): p. 402-6.

5. Acharya P, Acharya A. Evaluation of Applicability of Standard Growth Curves to Indian Women by Fetal Biometry. JSAFOG. 2009 September-December; 1(3): p. 55 - 61.

6. Akhtar W, Ali A, Arain M, Saeed F, Siddiqui S. Sonographic fetal biometry charts for a Pakistani cohort. Eastern Mediterranean Health Journal. 2011 December; 12(17): p. 969-75.

7. Al-Bayyari N, Abu-Heija A. Fetal weight normograms for singleton pregnancies in a jordanian population. Annals of Saudi Medicine. 2010 March; 2(30): p. 134-40.

8. Araujo J, Martins SE, Martins WP, Ruano R, Pires CR, al e. Reference charts of fetal biometric parameters in 31,476 Brazilian singleton pregnancies. Ultrasound Med. 2014 July; 7(33): p. 11851191. 


\section{Sharma et al; Assessment of fetal gestatianal age}

9. Ashrafunnessa, Jehan AH, Chowdhury SB, Sultana F, Haque JA, Khatun S, et al. Construction of fetal charts for biparietal diameter, fetal abdominal circumference and femur length in Bangladeshi population. Bangladesh Med Res Counc Bull. 2003 August; 2(29): p. 67-77.

10. Brooksidepress.org. The Brooksidepress Associates. [Online]; $2009 . \quad$ Available from: http://www.brooksidepress.org/Products/Military_OBGYN/Ultraso und/2ndand3rdTrimesterUltrasoundScanning.

11. Salpou LJ, Rasmuss S. BioMed Central. [Online].; 2008. Available from: http://www.biomedcentral.com/1471-2393/8/48

12. Snijders RJ, Nicolaides KH. Fetal bioletry at 14-40 weeks' gestation. Ultrasound Obstet Gynecol. 1994 Jan; 4(1): p. 34-48.
13. de la Vega A, Ruiz-Febo N, Roberts ZC. Fetal ultrasound biometry: normative charts for a Puerto Rican population. $\mathrm{P} \mathrm{R}$ Health Sci J. 2008 March; 1(27): p. 81-84.

14. Babuta S, Chauhan S, Garg R, Bagarhatta M. Assessment of fetal gestational age in different trimesters from ultrasonographic measurements of various fetal biometric parameters. Journal of Anatomical Society of India. 2013 June; 62(1): p. 40-46.

15. Kinare AS, Chinchwadkar MC, Natekar AS, Coyaji KJ, Will AK, Joglekar CV, et al. Patterns of Fetal Growth in a Rural Indian Cohort and Comparison With a Western European Population: Data From the Pune Maternal Nutrition Study. Journal of Ultrasound in Medicine. 2010; 2(29): p. 215-223.

Copyright: () the author(s), publisher. Academia Anatomica International is an Official Publication of "Society for Health Care \& Research Development". It is an open-access article distributed under the terms of the Creative Commons Attribution Non-Commercial License, which permits unrestricted non-commercial use, distribution, and reproduction in any medium, provided the original work is properly cited.

How to cite this article: Sharma H, Sharma DK, Sharma I. Assessment of Fetal Gestational Age in Different Trimesters from Ultrasonographic Measurements of Biparietal Diameter in the Region of Udaipur. Acad. Anat. Int. 2019;5(2):84-89.

DOI: dx.doi.org/10.21276/aanat.2019.5.2.23

Source of Support: Nil, Conflict of Interest: None declared. 